\title{
Pancreaticobiliary obstruction following duodenal stent placement
}

A 58-year-old woman underwent endoscopic management of malignant duodenal obstruction secondary to a pancreatic head mass. Baseline laboratory tests demonstrated mild transaminasemia without cholestasis. On endoscopy, a malignant stricture was seen at the distal end of the bulb, and fluoroscopic images verified involvement of the proximal $2 \mathrm{~cm}$ of the descending portion. A through-the-scope $22 \times 60-\mathrm{mm}$ duodenal self-expandable metal stent (SEMS; WallFlex, Boston Scientific, Natick, Massachusetts, USA) was deployed, with no immediate complications observed ( $\bullet$ Fig. 1 ).

The patient subsequently complained of new-onset epigastric pain, and laboratory analysis revealed acute pancreatitis, progressive cholestasis, transaminasemia, and mild leukocytosis ( Fig.2). The enteral stent was retrieved with minimal mucosal trauma. Over the next 48 hours the epigastric pain improved and laboratory results started to return to normal. The patient underwent an uncomplicated pancreaticoduodenectomy, and surgical pathology revealed invasive pancreatic adenocarcinoma with direct invasion of the duodenum, though no pancreaticobiliary or ampullary involvement.

Severe complications of duodenal stents are rare, whereas errors of deployment, migration, and stent obstruction occur more frequently [1-3]. Although pancreaticobiliary obstruction has been documented, direct tumor invasion of the ductal system has consistently been implicated $[4,5]$. In the present case, clinical and laboratory evidence of obstructive cholestasis and acute pancreatitis were temporally consistent with stent-induced ampullary compression, which was further supported by a surgical specimen with no findings of ductal involvement.

The majority of approved enteral stents employ an uncovered self-expanding wire mesh, and recent data demonstrate equivalent efficacy and 8-week patency between covered and uncovered SEMSs in patients with malignant pyloric obstruction [6]. However, the overall clinical experience with covered duodenal SEMS is limited, and we suspect that covered SEMS may induce more pancreaticobiliary obstruction. In practice, the wire

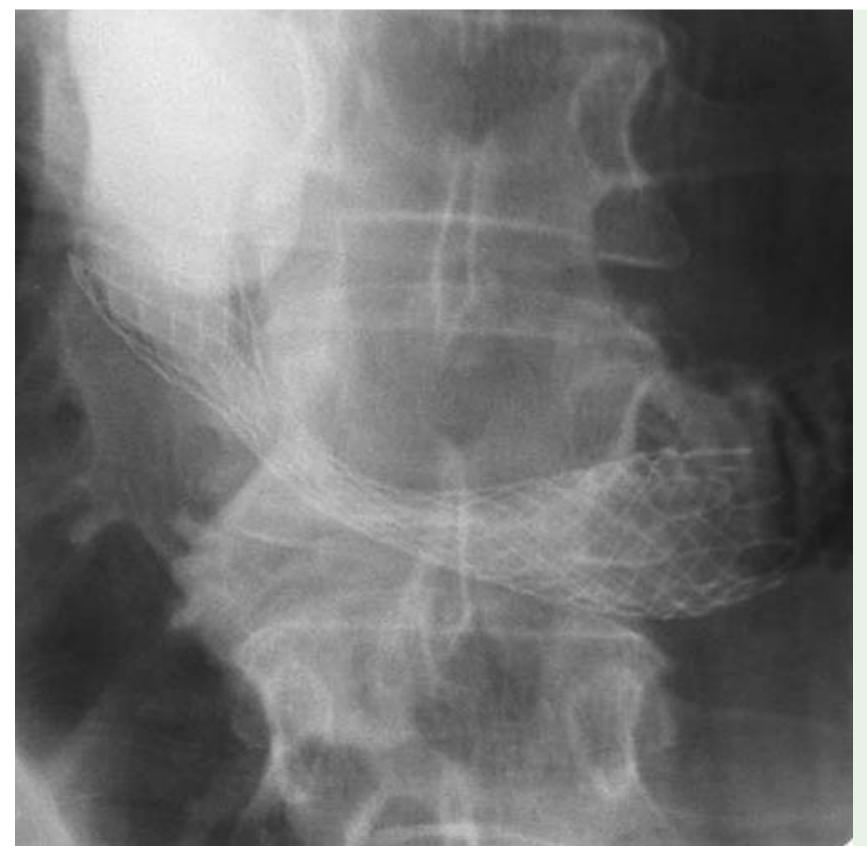

Fig. 1 Fluoroscopic view of the deployed enteral stent with a 2-cm waist corresponding to the duodenal stricture.

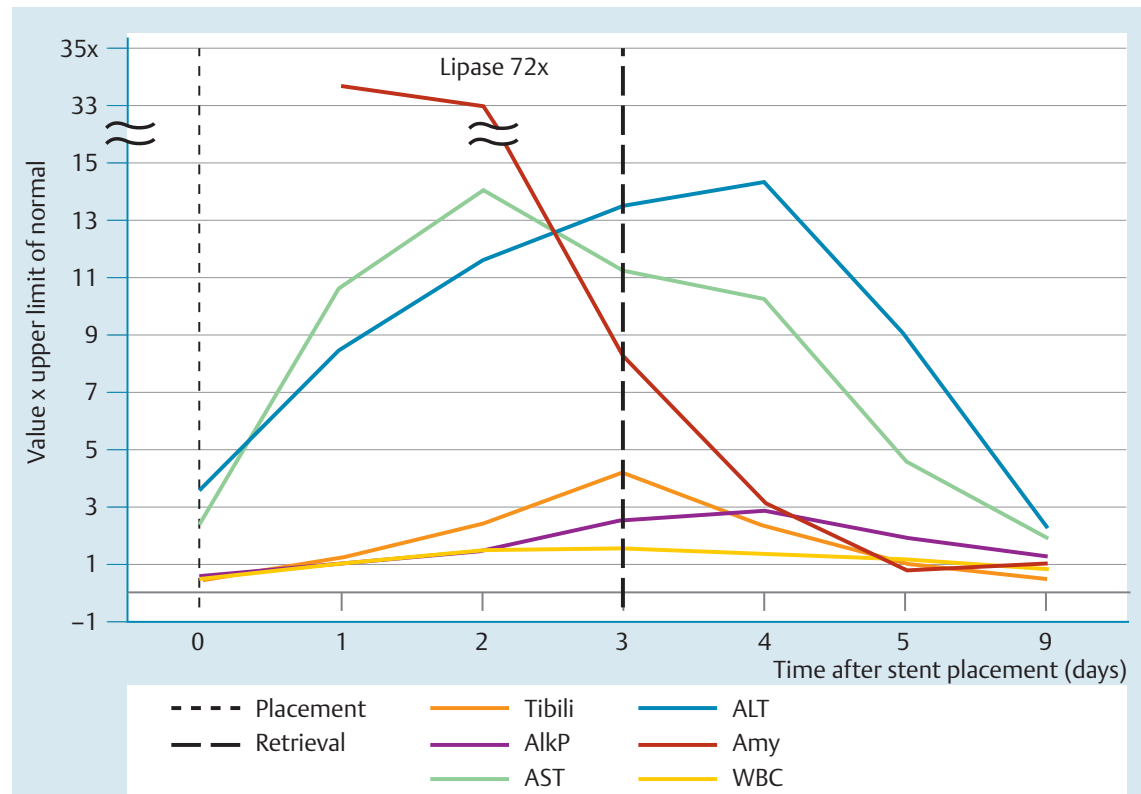

Fig. 2 Laboratory data showing obstructive cholestasis and acute pancreatitis with subsequent normalization temporally consistent with stent deployment and retrieval, respectively. Tibili, total bilirubin; AlkP, alkaline phosphatase; AST, aspartate aminotransferase; ALT, alanine aminotransferase; Amy, amylase; WBC, white blood cell count.

mesh of uncovered SEMSs is likely to compress the major papilla, although the orifice presumably remains patent in the majority of cases, perhaps due in part to sphincter resistance. We propose that a confluence of factors led to ampullary ob- struction in the present case, including mechanical stent compression of a compromised periductal anatomy ( Fig.3). The frequency of such a complication is likely to be underestimated and underappreciated, given the high number of 


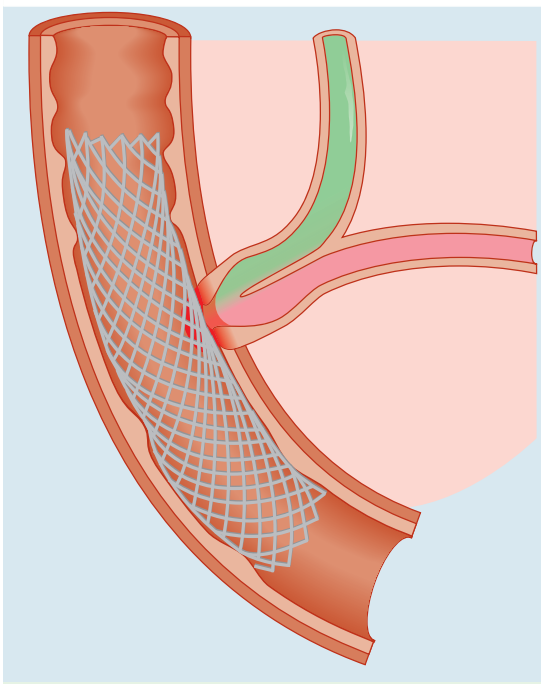

Fig. 3 Schematic representation of pancreaticobiliary obstruction due to iatrogenic compression of the major papilla by an uncovered duodenal self-expandable metal stent.

individuals who undergo prophylactic or therapeutic pancreaticobiliary stent deployment due to current or impending direct malignant extension.

Endoscopy_UCTN_Code_CPL_1AH_2AD

\section{S. K. Amateau ${ }^{1}$, C. L. Wolfgang ${ }^{2}$, M. A. Khashab ${ }^{1}$}

${ }^{1}$ Department of Internal Medicine, Division of Gastroenterology and Hepatology, The Johns Hopkins Hospital, Baltimore, Maryland, USA

${ }^{2}$ Department of Surgery, Sol Goldman Pancreatic Cancer Research Center, The Johns Hopkins Hospital, Baltimore, Maryland, USA

\section{References}

1 Graber I, Dumas R, Filoche B et al. The efficacy and safety of duodenal stenting: a prospective multicenter study. Endoscopy 2007; 39: 784-787

2 Mauro MA, Koehler RE, Baron TH. Advances in gastrointestinal intervention: the treatment of gastroduodenal and colorectal obstructions with metallic stents. Radiology 2000; 215: 659-669

3 Phillips MS, Gosain S, Bonatti H et al. Enteral stents for malignancy: a report of 46 consecutive cases over 10 years, with critical review of complications. J Gastrointest Surg 2008; 12: $2045-2050$

4 van Hooft J, Mutignani M, Repici A et al. First data on the palliative treatment of patients with malignant gastric outlet obstruction using the WallFlex enteral stent: a retrospective multicenter study. Endoscopy 2007; 39: 434-439
5 van Hooft JE, Uitdehaag MJ, Bruno MJ et al. Efficacy and safety of the new WallFlex enteral stent in palliative treatment of malignant gastric outlet obstruction (DUOFLEX study): a prospective multicenter study. Gastrointest Endosc 2009; 69: 1059-1066

$6 \mathrm{Kim}$ CG, Choi IJ, Lee JY et al. Covered versus uncovered self-expandable metallic stents for palliation of malignant pyloric obstruction in gastric cancer patients: a randomized, prospective study. Gastrointest Endosc 2010; 72: $25-32$

\section{Bibliography}

DOI http://dx.doi.org/

10.1055/s-0031-1291500

Endoscopy 2012; 44: E17-E18

(c) Georg Thieme Verlag KG

Stuttgart · New York

ISSN 0013-726X

\section{Corresponding author}

\section{A. Khashab, MD}

The Johns Hopkins Hospital 1830 East Monument Street

Room 426

Baltimore

Maryland 21205

USA

Fax: +1-410-502-0198

mkhasha1@jhmi.edu

\section{Competing interests: None}

